\title{
Accessibility problems in home environment for seniors in Latvia: Experience from the research project innovAge (WP2)
}

\author{
S. Tomsone, L. Saukuma, Z. Liepina, and J. Zalkalns \\ Rīga Stradiņš University, Riga, Latvia
}

\begin{abstract}
Studies on relations between health and environment indicate that accessibility positively influence healthy life expectancy, as accessible home environment and neighbourhood support mobility, daily activities and social participation in old age. One of the tasks in the EC 7th framework research project innovAge (2012-2015) aimed to develop an IT tool to support seniors' involvement in decisions about their housing options and help them to become active partners in choice and supply of housing.

This study aims to explore seniors' opinions about accessibility in their physical home environment based on analysis of data - interview records and notes - from two study stages in the research project innovAge (WP2). Participants, at the first stage -8 seniors and at the second stage -10 seniors, represented variety of living conditions, family situations and functional abilities. Participation in the study was voluntary and the participants had right to withdraw from the study at any stage.

Usually, barriers in home environment seniors consider late, when functional abilities decreases substantially. The most common places where environmental barriers appear are sanitary spaces, kitchen and entrance of the home. Despite the environmental barriers and functional limitations, seniors remain in their homes, mainly because in Latvia do not exist traditions to seek options for relocation, as well as there are no policies and services to support this. In few municipalities options exist to adapt home environment, but it refers only to cases of severe disability for persons using wheelchair. Usually, the need for environment adaptations for seniors is replaced by care services, thus meeting also the needs for seniors' socialization. Regarding possibilities to adapt home environment, strong prejudices exist (bath vs. shower, disadvantages of living on the first floor, etc.). Seniors admitted that they lack knowledge and experience on housing adaptations, but emphasized that the environmental accessibility in a wider context, including the neighbourhood and services, is essential.

The close cooperation with participants facilitated the researchers' understanding of the seniors' complex views and needs regarding their home environment and related issues, which are important for developing housing policies for senior citizens in Latvia. Despite the specified accessibility problems in home environment, the seniors evaluated usability of their homes generally high.
\end{abstract}

Key words: project innovAge, seniors, accessibility, housing. 


\section{Introduction}

Populations are rapidly aging and more people are expected to live longer with disabilities and reduced functional capacity [1]. Such trends involve major societal challenges, e.g. increased demands for accessible housing that supports active and healthy ageing.

Social innovations are considered as one of solutions for global challenges risen by the rapidly ageing population. Social innovations defined as new ideas (products, services and models) that strive to address pressing current needs; they simultaneously meet social needs (more effectively than alternatives) and create new social relationships or collaborations [2]. The EC 7th framework research project innovAge (2012-2015) was dedicated to developing and testing, as well as surveying and cataloguing, social innovations that will have a solid impact on improving the quality of life and well-being of older people [3]. One of the tasks aimed to develop an ICT tool to support seniors' involvement in decisions about their housing options and help them to become active partners in choice and supply of housing.

The home is the most important living space of older people where most things in daily life happen [4]. Research on housing and health among very old people in Europe has shown that home and neighbourhood environments affect older people's daily activities and participation, and adequately designed housing affects independence positively $[5,6]$. It is widely known that participation in daily activities gives meaning to people's lives and is considered a determinant of well-being and health [7]. Older people themselves stress the importance of having a functional and secure home in order to be as independent and autonomous as possible in daily activities and maintain participation [8].

Studies on relations between health and environment indicate that accessibility positively influence healthy life expectancy, as accessible home environment and neighbourhood support mobility, daily activities and social participation in old age. Accessibility can be defined as the relationship between a person's functional capacity and the prevalence of physical environmental barriers in the environment. According to this definition, accessibility is an aspect of person-environment fit (P-E fit) [9].

One well-established research-based instrument, available for professional assessments of housing accessibility, is the Housing Enabler (HE) $[10,11]$. It is useful not only for research and education but also to support practitioners in producing reliable and valid assessments as a basis for interventions targeting housing accessibility problems, at individual and group levels [11]. The HE consists of a three-step assessment and analysis based on one checklist of functional capacity in the individual (personal component) and one checklist of environmental barriers (environmental component), followed by an analysis of P-E fit resulting in a quantitative measurement of accessibility problems [10]. Research using the HE has shown that environmental barriers are common in housing across Europe [12].

In Latvia there are not much studies conducted to explore the older people's needs regarding environment, especially their home environment. According to results from Project ENABLE-AGE (2002-2004) participants in Latvia had lower housing standard but presence of environmental barriers was quite similar with situation in Germany and Sweden [12]. Eurostat statistics on living conditions showed that in Latvia about $65 \%$ of the population lived in apartments in multi-family housing [13]. According to EU-SILC data [14], Latvia had Europe's highest overcrowding rate for housing at $58 \%$ of the population (the average for European countries is 18\%). As to the situation of senior citizens in society, in the Active Ageing Index (AAI) across EU member states Latvia is among the countries at the bottom [15]. The aim of the present study was to explore seniors' opinions on accessibility in their physical home environment. 


\section{Materials and methods}

The present study is based on Latvian results from one part (WP2) of the innovAge project, financed by the European Commission (2013-2015). The WP2 targeted people aging with functional limitations to raise their awareness about accessibility issues in their current dwellings and in available rental apartments within the ordinary housing stock. The ambition was to develop the ICT tool based on methodology of the Housing Enabler (HE) that would support decision-making and to make it possible for users, older people, to get an overview and make predictions about housing accessibility in relation to their present or projected functional capacity. Participants from Latvia were involved in research circles [16] in order to generate knowledge of how senior citizens express their own needs and expectations regarding housing options, and to establish the users' requirements for a housing accessibility ICT tool [17] as well as in usability testing of ICT tool prototype.

The common sampling procedures and strategy for data collection were used in all countries (Sweden, Germany, Italy and Latvia) participating in WP2 of project innovAge and they are described elsewhere $[17,18]$ and Table 1 shows details for both data collection stages in Latvia. The first step of the project in Latvia involved 8 senior participants, and the second stage - 10 seniors, they represented variety of living conditions, family situations and functional abilities $[17,18]$. Participation in the study was voluntary and the participants had right to withdraw from the study at any stage.

Interview records and notes from both study stages in Latvia were analyzed for present study. Primary data were reviewed by authors separately and information units related to accessibility aspects were extracted. Extracted information was discussed by the authors and organized into three main topics - information, recognition of problems and solutions.

Table 1. Information on two stages of data collection in Latvia (research project innovAge, WP2).

\begin{tabular}{|r|c|c|}
\hline & Research circle & IT tool test \\
\hline Research sites & $\begin{array}{c}\text { in Sweden, Latvia, } \\
\text { Germany and Italy }\end{array}$ & in Sweden and Latvia \\
\hline Participants in Latvia $(\boldsymbol{N})$ & 8 & 10 \\
\hline Research team & Researcher and assistant & Researcher and assistant \\
\hline Other participants & Experts & - \\
\hline $\begin{array}{r}\text { Structure and } \\
\text { organization }\end{array}$ & Guidelines & Guidelines \\
\hline Data & $\begin{array}{c}\text { Audio records, } \\
\text { transcripts, researchers } \\
\text { notes }\end{array}$ & $\begin{array}{c}\text { Video/audio records, } \\
\text { questionnaires, researchers } \\
\text { notes }\end{array}$ \\
\hline
\end{tabular}

\section{Results and discussion}

For seniors in Latvia accessibility problems in home environment were related to information about accessibility, recognition of problems and possibilities to solve them.

\subsection{Accessible housing-information}

Participants stressed lack of information on accessibility problems (potential hazards, longterm consequences of more or less accessible environment) and their potential impact on everyday life. They considered that more knowledge of impact that different environmental barriers can have on individuals is important to raise awareness about one's own environment and to facilitate ability to initiate changes in order to make housing more accessible. Seniors perceived that it was difficult to find suitable information on accessible 
environments. They emphasized that the environmental accessibility is essential in a wider context - including the neighbourhood and services (e.g. public transport).

\subsection{Accessible housing - recognition of problems}

The general belief was that individuals do not become aware of environmental influences until something happens to them affecting their day-to-day life, when functional abilities decrease substantially and supportive environment becomes more important. The specific features of home design were well recognized; e.g. Soviet time standards for housing typically means small living space, narrow doors and passages which are difficult to adapt. Most often accessibility problems in home environment were recognised in hygiene facilities (only bath instead of shower, lack of handles for support and lack of other assistive devices useful for bathing), kitchen (narrow spaces for moving around, high shelves) and entrance in house (steps in front of doors, poor condition of walking surfaces, lack of handrails near stairs). Technical problems in communal areas of houses also were mentioned, e.g. elevators do not work properly or lightning is poor.

\subsection{Accessible housing - solutions}

Despite the environmental barriers and increasing functional limitations, seniors remain in their homes, mainly because there do not exist traditions to seek options for relocation in Latvia as well as there are no policies and services to support such relocation. Seniors are dealing with very limited private financial resources and therefore issue of high costs was brought up associated with refurbishment, housing adaptations, or rents in newly built accessible housing. The participants viewed themselves as badly informed on existing laws and regulations regarding housing adaptation or on whom to contact in order to receive information on accessible housing. In few municipalities in Latvia exist options to support adaptations at home but it implies only in case of severe disability for persons using wheelchair (only three out of the 118 municipalities in the country provide housing adaptation grants). Usually, the need for environment adaptations for seniors is replaced by care services (e.g. care assistant), thus meeting also the needs for senior's socialization. Regarding possibilities to adapt home environment exist strong prejudices (bath vs. shower - use less water and save expenses on water, disadvantages of living on the first floor, etc.). Personal creativity was mentioned as a possible recourse to solve problems arising from inappropriate environment, e.g. refurnishing in order to get more space or to get better support to move around.

\section{Conclusions}

The close cooperation with older people facilitated the researchers' understanding of the seniors' complex views and needs regarding their home environment and related issues, which are important for developing housing policies for senior citizens in Latvia. Despite the specified accessibility problems in home environment, the seniors generally evaluated usability of their homes as high.

The innovAge project was part of Social Innovations Promoting Active and Healthy Ageing, HEALTH.2012.3.2-3 No. 306058 within the 7th EU framework programme. The authors would like to thank all project participants, consortium and team members for their contribution. The authors are specifically grateful to WP 2 leading team from Lund University (Sweden) - Prof. Susanne Iwarsson, Prof. Torbjörn Svensson, Björn Slaug, Maria Haak, Thomas Ladö, Steven M. Schmidt, Oskar Jonsson and Knut Mårtensson. 


\section{References}

1. A.B. Newman, J.A. Cauley, (Eds.) The epidemiology of ageing. Dordrecht, Germany: Springer, 2012

2. R. Murray, J. Caulier-Grice, G. Mulgan. The Open book of Social Innovations. The Young foundation and NESTA: London, UK, 2010

3. About project innovAge. Retrieved May 2016 from http://www. innovage. group.shef.ac.uk/about-innovage.html

4. R. Chilvers, S. Corr, H. Singlehurst. Investigation into the occupational lives of healthy older people through their use of time. Australian Occupational Therapy Journal, 2010, (57) 24-33

5. F. Oswald, H.-W. Wahl, O. Schilling, C. Nygren, A. Fänge, A. Sixsmith, J. Sixsmith, Z. Széman, S. Tomsone, S. Iwarsson. Relationships between housing and healthy ageing in very old age. Gerontologist, 2007, 47(1), 96-107

6. H.-W. Wahl, A. Fänge, F. Oswald, L.N. Gitlin, S. Iwarsson. The home environment and disability-related outcomes in ageing individuals: What is the empirical evidence? Gerontologist, 2009, 49(3), 355-367

7. E. Townsend, H. Polatajko (Eds.). Enabling occupation II: Advancing and occupational therapy vision for health, well-being \& justice through occupation. Ottawa: Canadian Association of Occupational Therapists, 2013

8. M. Haak, A. Malmgren Fänge, S. Iwarsson, S. Dahlin-Ivanoff. The importance of successful place integration for perceived health in very old age: a qualitative metasynthesis. Int J Public Health, 2011, 56(6), 589-595

9. S. Iwarsson, A. Ståhl. Accessibility, usability and universal design - Positioning and definition of concepts describing person-environment relationships. Disabil Rehabil $2003 ; 25,57-66$

10. S. Iwarsson, B. Slaug. Housing Enabler - A method for rating/screening and analysing accessibility problems in housing. Manual for the the complete instrument and screening tool, $2^{\text {nd }}$ rev ed.; Veten \& Skapen HB och Slaug EnablingDevelopment:Lund \& Staffanstorp, Sweden, 2010

11. S. Iwarsson, M. Haak, B. Slaug. Current developments of the Housing Enabler methodology. Br. J. Occup. Ther., 2012, 75(11), 517-521

12. S. Iwarsson, C. Nygren, F. Oswald, H.-W. Wahl, S. Tomsone. Environmental barriers and housing accessibility problems over a one-year period in later life in three European countries. J. Hous. Elderly, 2006, 20(3), 23-43

13. Living conditions in Europe (2014). Eurostat statistical books. Retrieved May 2016

from http: //ec.europa.eu/eurostat/documents/3217494/ 6303711/KS-DZ-14-001-EN-N.pdf/d867b24b-da98-427d-bca2d8bc212ff7a 8

14. EU-SILC data (2012). Retrieved May 2016 from http: / / ec . europa. eu/ eurostat/web/income-and-living-conditions/data/maintables

15. A. Zaidi. Active ageing index: A legacy of the European year 2012 for active ageing and solidarity between generations. 2015. Retrieved May 2016 from http://www. euro.centre.org/detail.php?xml id=2489

16. M. Kylberg, M. Haak, A. Ståhl, E. Skogh, S. Iwarsson. Re-search brief \#5: User participation. Research with and about user participation. Stockholm, Sweden: Forte [Swedish Research Council for Health, Working Life and Welfare], 2015

17. M. Haak, B. Slaug, F. Oswald, S. Schmidt, J.M. Rimland, S. Tomsone, T. Ladö, T. Svensson, S. Iwarsson. Cross-national user priorities for housing provision and 
accessibility - Findings from the European innovAge project. International Journal of Environmental Research and Public Health, 2014, 12(3), 2670-2686

18. O. Jonsson, M. Haak, S.Tomsone, S. Iwarsson, S.M. Schmidt, K. Mårtensson, T. Svensson, B. Slaug. Cross-national Usability Testing of a Housing Accessibility App: Findings from the European innovAge project. Journal of Usability Studies, 2016, 12(1), 26-49 